\title{
아래덧눈꺼풀교정술과 최소 절개 안쪽눈구석주름교정술의 임상결과 Clinical Outcomes of Lower Eyelid Epiblepharon Repair Combined with Minimal Incision of Medial Epicanthoplasty
}

\author{
안지선 · 김정희 · 이경욱 \\ Ji Seon An, MD, Jeong Hee Kim, MD, Kyeong Wook Lee, MD \\ 새빛안과병원 \\ Saevit Eye Hospital, Goyang, Korea
}

\begin{abstract}
Purpose: To introduce a method of correcting lower eyelid epiblepharon with severe epicanthal fold combined with minimal incision of medial epicanthoplasty (Hiraga method) and to report its clinical outcomes.

Methods: We retrospectively reviewed the medical records of patients who underwent surgery for lower eyelid epiblepharon and minimal incision of medial epicanthus from January 2015 and January 2019. Seventy-eight eyes of 39 patients were analyzed for surgical outcomes, subjective symptoms, recurrence, and complications for more than six months of the follow-up period.

Results: A total of 39 patients ( 14 male, 25 female) were included in the analysis. The mean patient age was $8.4 \pm 4.3$ years, and the mean postoperative follow-up was $14 \pm 5.2$ months. Eyelid shape and function were well maintained in 39 patients $(100 \%)$, with no recurrence during follow-up.

Conclusions: For patients with lower eyelid epiblepharon with severe medial epicanthal fold, lower eyelid epiblepharon with a minimal incision of medial epicanthoplasty (Hiraga method) is a simple surgical technique to prevent recurrence of medial cilia touch, showing successful results without complications.
\end{abstract}

J Korean Ophthalmol Soc 2020;61(6):591-596

Keywords: Epiblepharon, Epicanthus, Hiraga method, Lower eyelid

아래덧눈꺼풀의 발생 원인으로는 크게 두 가지로, 1차적 으로 과도한 피부 및 눈둘레근으로 인한 수직 벡터의 원인 과 2차적으로 안쪽눈구석 주름으로 인한 접선 벡터의 원인 이 있다. ${ }^{1-4}$ 동양인의 경우는 특히 안쪽눈구석 주름이 흔한 데 이는 안쪽눈구석 눈꺼풀의 피부, 눈둘레근이 두껍고 피 하지방이 많으며 앞 눈꺼풀판 주름이 이완되어 있고 안쪽

- Received: 2019. 12. 30.

- Revised: 2020. 2. 20.

- Accepted: 2020. 5. 17.

- Address reprint requests to Kyeong Wook Lee, MD Saevit Eye Hospital, \#1065 Jungang-ro, Ilsandog-gu, Goyang 10447, Korea

Tel: 82-31-900-7700, Fax: 82-31-900-7777

E-mail:1kw740306@hanmail.net

* Conflicts of Interest: The authors have no conflicts to disclose.
눈구석 피부 및 피부 밑 조직들이 풍부하여 안쪽눈구석 주 름이 흔하기 때문이다. ${ }^{5,6}$ 이러한 특성으로 인해 안쪽눈썹찔 림의 경우 전체 눈썹찔림의 $58.6 \%$ 에 해당되며 특히 안쪽눈 썹찔림의 재발률은 재발의 가장 흔한 형태이다. ${ }^{7}$

아래덧눈꺼풀 교정 시 1 차 원인인 과도한 피부 및 눈둘 레근은 일반적인 덧눈꺼풀교정수술을 이용하여 교정할 수 있으나 2차 원인인 안쪽눈구석주름이 심한 경우 기존의 덧 눈꺼풀수술만으로는 교정이 안되기 때문에 별도의 안쪽눈 구석주름교정술을 함께 시행하게 된다. 안쪽눈구석주름교 정술은 Mustardé법, ${ }^{8}$ 변형된 Y-V 앞옮김술(modified Y-V advancement), ${ }^{9,10}$ 뿌리 Z-안쪽눈구석주름교정술(root Z-epicanthoplasty), ${ }^{5,10}$ 피부재배치법(skin-redraping epicathoplasty) ${ }^{3,11}$ 등이 있으나 도안 및 절개 방법이 복잡하여 초심자가 하기 어렵고 일부 수술의 경우 과도한 절개로 인한 안쪽눈구석 
및 코쪽 반흔이 잘 생길 수 있다. 이에 본 저자들은 아래덧 눈꺼풀과 심한 안쪽눈구석주름이 동반된 경우 아래덧눈꺼 풀교정술 시에 기존의 안쪽눈구석주름교정술보다 도안이 쉽고 수술 방법이 간편한 최소 절개 안쪽눈구석주름교정술 방법(히라가 법)을 소개하고, 이 방법의 임상결과를 보고하 고자 하였다.

\section{대상과 방법}

2015년 1월부터 2019월 1월 사이 아래덧눈꺼풀교정 술과 최소절개 안쪽눈구석주름교정술을 함께 받은 환자 39 명의 환자를 대상으로 의무기록을 후향적으로 조사하 였다. 본 연구는 모든 과정에서 헬싱키선언(Declaration of Helsinki)을 준수하였으며, 본원 임상연구 윤리위원회 (Institutional Review Board, IRB)의 승인을 받았다(승인 번 호: 201912-001-01). 수술은 술 전 세극등검사상 아래덧눈 꺼풀로 인한 자각적 불편감과 타각적 각막병변 소견이 있 는 경우 시행하였으며, 안쪽눈구석주름 유형 중 눈꺼풀사 이눈구석주름(epicanthus palpebralis)으로 인한 내측 눈썹 찔림이 많은 환자들을 대상으로 한 명의 술자에 의해 수술 이 시행되었다.

수술 방법은 다음과 같다. 디자인 방법의 경우 안쪽눈구 석교정술을 위한 히라가 법은 안쪽눈구석에 해당하는 피부 지점을 표시하기 위해서 안쪽눈구석주름을 코쪽으로 잡아 당겨 눈구석이 보이게 한 후, 마킹펜을 눈구석 자리에 가만 히 고정하여 두고 당겼던 눈구석 피부를 놓으면 당겨졌던 코쪽 피부가 제자리로 돌아가면서 안쪽눈구석에 해당하는 지점의 피부에 새로운 안쪽눈구석을 표시한 후 안쪽눈구석 주름 경계까지 수평으로 선을 연장하였다(Fig. 1). 덧눈꺼풀 교정술 피부절개선의 위쪽 경계는 눈꺼풀테와 평행하게 $1 \mathrm{~mm}$ 떨어진 곳에 표시하였는데 안쪽은 안쪽눈구석부위까
지, 바깥쪽은 눈썹찔림이 없는 부위까지 수평으로 표시한 후 술 후 귀 모양 변형을 방지하기 위해 사선으로 아래쪽 경계선까지 연결하였다. 아래쪽 경계는 접힌 피부선(folded skin line)에 맞춰서 그려주며 새로운 안쪽눈구석을 표시한 부분과 연결하여 도안을 완성하였다.

$2 \%$ lidocaine과 1:100,000 epinephrine을 혼합하여 안쪽 눈구석주름과 아래눈꺼풀 수술 부위 피부 밑으로 주사한 후, 안쪽눈구석주름 교정을 위해 Stevens scissors를 이용하 여 안쪽눈구석주름 절개선을 따라 피부 및 안쪽눈구석주름 을 형성하고 있는 근육섬유조직을 절개하였다. 이후 아래 덧눈꺼풀 교정을 위해 Bard-Parker 15번 칼을 사용하여 위, 아래 피부 절개선을 따라 절개하고 피부와 눈둘레근을 같 이 전기소작기를 이용하여 지혈을 하면서 절제한 후 눈꺼 풀판 앞 눈둘레근의 일부를 Stevens scissors를 이용하여 제 거하였다. 속눈썹회전봉합술에 앞서 피부재배치를 하기 위해 안쪽눈구석과 새로운 눈구석 표시점의 피부 밑을 6-0 vicryl 로 매몰봉합을 하였다. 속눈썹 회전봉합술은 8-0 nylon을 이용하여 2군데(내측각막윤부위치, 동공중앙위치) 시행하 였다. 피부봉합은 6-0 fast absorbing plain gut으로 안쪽눈 구석주름교정술 부위는 1군데 단속봉합을, 나머지 피부는 연속봉합을 하였다(Fig. 2). 수술이 끝날 때 항생제 연고 (Tarivid $^{\circledR}$, Ofloxacin $3 \mathrm{mg} / \mathrm{g}$, Santen Pharmacia, Seoul, Korea) 를 수술 부위에 도포하였고 수술 7일째까지 항생제 연고를 봉합 부위에 바르게 하였다. 수술 결과는 최소 6 개월 이상 경과 관찰하였고 외래 방문 시 주관적인 자각 증상의 소실 여부와 세극등검사를 이용하여 객관적인 수술 부위 합병증 의 발생 및 눈썹 찔림의 재발 유무를 관찰하였다.

\section{결 과}

총 39 명의 심한 안쪽눈구석주름을 동반한 아래덧눈꺼풀
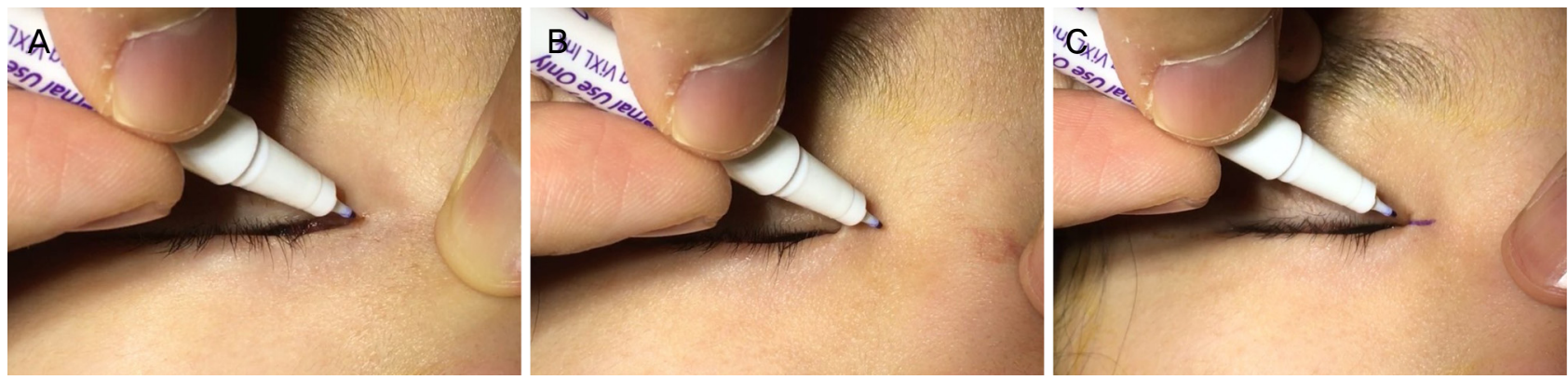

Figure 1. Hiraga design. (A) Pull the medial epicanthal fold toward the nose to make the epicanthus visible, and then hold the pen in the place of epicanthus. (B) If you release the pulled epicanthus, the pulled nose skin can return to its position and display the new medial epicanthus at the corresponding point. (C) Mark the skin incision lines horizontally from the medial epicanthus to the edges of the skin. 
환자 중 남자는 14 명(35.9\%), 여자는 25 명(64.1\%)이었고 평 균 나이는 $8.4 \pm 4.3$ 세였다. 수술 후 모든 환자에서 아래덧 눈꺼풀이 해결되었고 평균 $14 \pm 5.2$ 개월의 추적 관찰기간 동안 39 명 $(100 \%)$ 의 환자가 최종 경과 관찰 시점까지 아래 덧눈꺼풀의 재발 없이 눈꺼풀의 모양과 기능이 잘 유지가 되었으며 자각적 불편감도 없었다. 수술 후 아래눈꺼풀후
퇴나 안검외반, 반흔 형성 등의 기타 합병증은 발견되지 않 았다(Fig. 3).

\section{고 찰}

덧눈꺼풀은 속눈썹주위의 과도한 피부주름과 눈둘레근
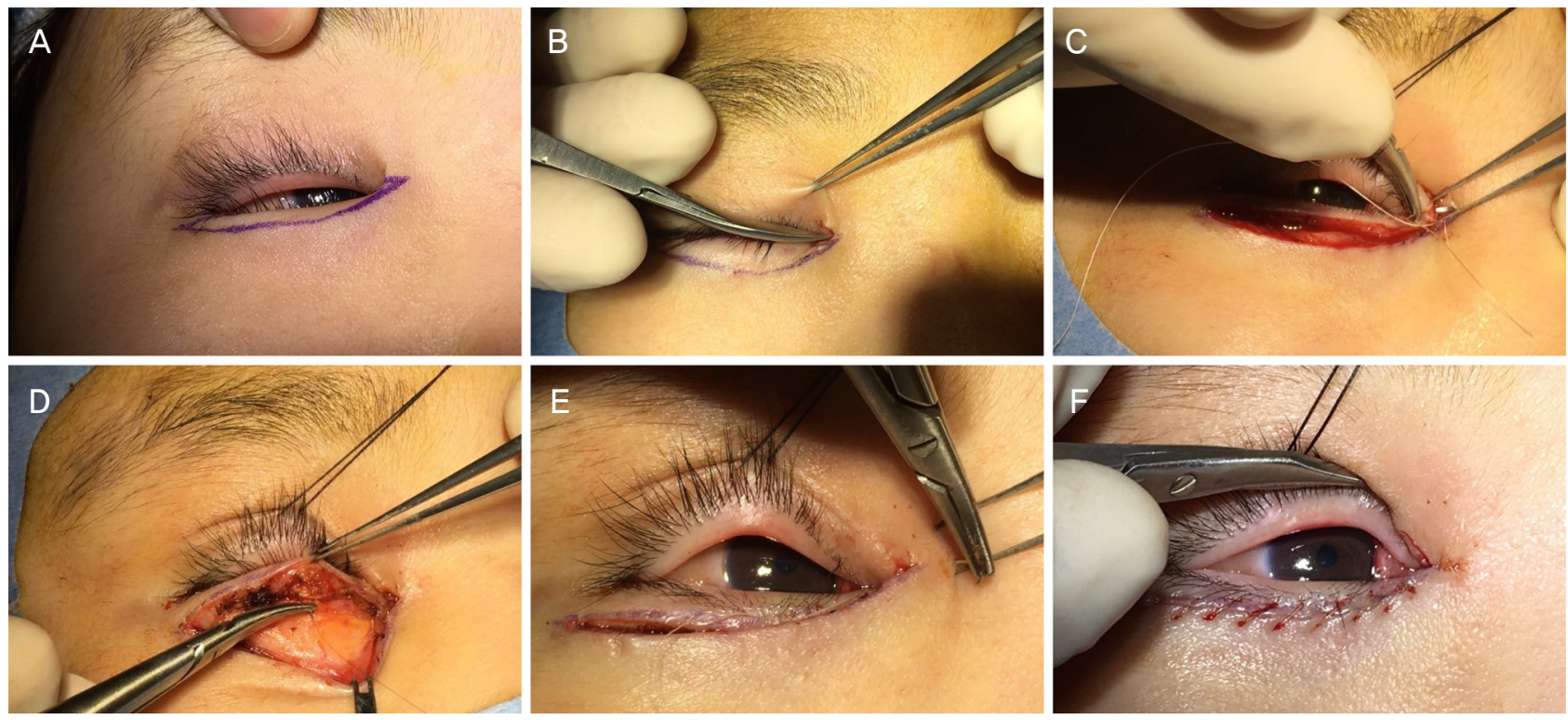

Figure 2. Clinical photographs of the surgical procedure. (A) Preoperative lower eyelid and medial epicanthus and the incision design. (B) Dissection at the medial epicanthus was performed by using Stevens scissors. (C) For reposition of the skin, subcutaneous suture was performed at medial epicanthus and newly marked epicanthus with 6-0 vicryl. (D) Cilia rotation suture was performed in 2 places using 8-0 nylon. (E) The suture by using 6-0 fast absorbing plain gut made a new medial epicanthus. (F) The skin incision was continuously sutured with 6-0 fast absorbing plain gut.
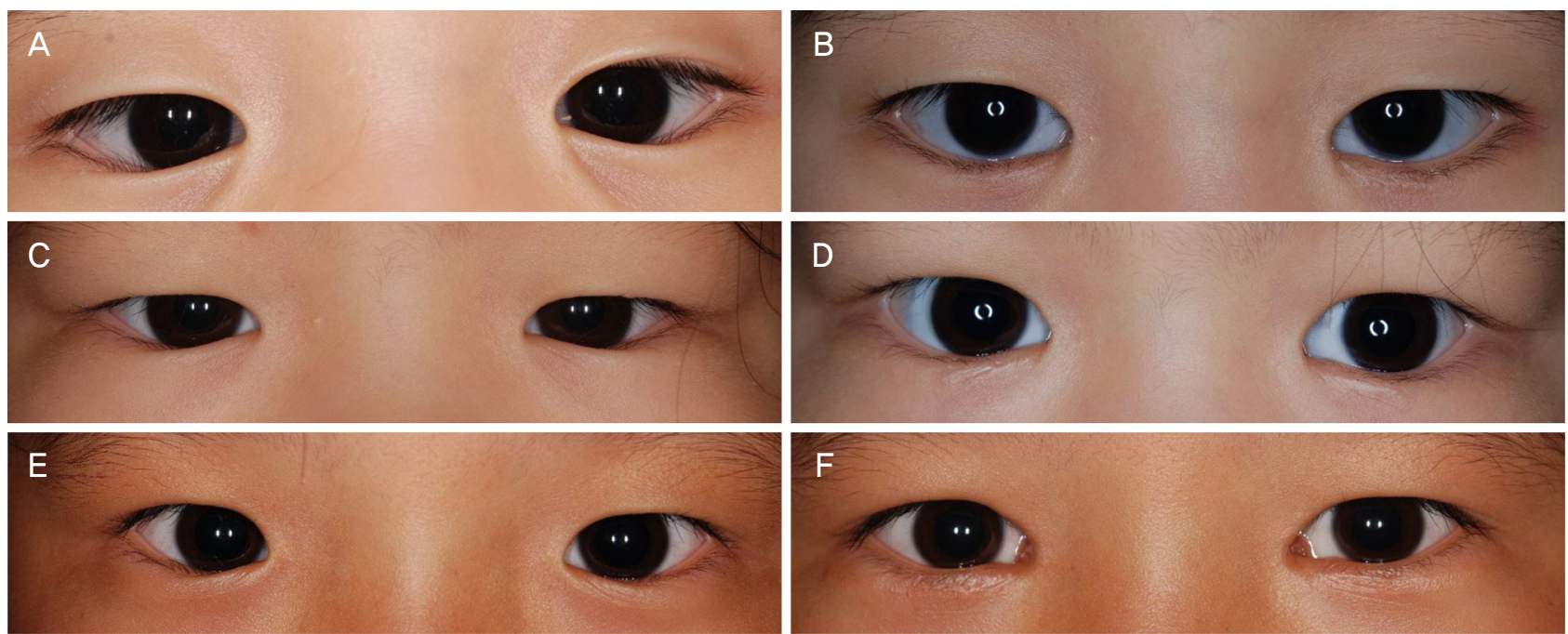

Figure 3. Photographs showing preoperative \& postoperative views. (A, C, E) Photographs of patients with lower eyelid epiblepharon with medial epicanthal fold preoperatively. (B, D, F) Patients' photographs after lower eyelid epiblepharon repair with minimal incision of medial epicanthoplasty by Hiraga method (12 months). 
이 눈꺼풀테 위로 겹쳐짐으로써 속눈썹이 눈쪽으로 밀려 각막과 결막을 자극하는 질환이다. 덧눈꺼풀은 우리나라를 포함한 동양 어린이에서 흔하게 발생하고 안쪽에 국한되어 아래 눈꺼풀에 주로 발생한다. ${ }^{5,6,12}$

덧눈꺼풀은 속눈썹이 각막 또는 결막에 닿아 각결막 자 극 및 손상, 눈물흘림 등의 증상을 일으키며 난시와 같은 굴절이상, 각막혼탁과도 연관이 있다고 보고되고 있다. ${ }^{13}$ 덧눈꺼풀은 어린 시절에 높은 발병률을 보이며 시간이 경 과함에 따라 자연히 호전될 수 있으나 약 $2 \%$ 에서 지속적인 증상을 나타낸다. ${ }^{14}$

아래덧눈꺼풀의 원인은 크게 두 가지로, 1 차적으로 과도 한 아래 피부주름 및 눈둘레근이 눈꺼풀테 위로 겹쳐짐으 로써 발생하거나 아래눈꺼풀당김기의 피부 밑 부착력 약화 로 인하여 눈꺼풀판 위로 피부주름이 전위되어서 발생하는 것으로 알려져 있으며 2차적으로 안쪽눈구석주름으로 인해 코쪽 피부가 눈둘레근을 접선 방향으로 당기는 원인이 있 을 수 있다. 이들 각각은 수직 벡터와 접선 벡터로 작용하 게 되며 이러한 이유로 눈썹이 안구 쪽을 향하게 되어 눈썹 과 각막의 접촉이 심해지게 되며, 특히 아래로 볼 때 그 정 도가 더욱 심해지게 된다. ${ }^{1-4,15}$

전통적인 아래덧눈꺼풀교정술은 과도한 피부둘레근을 절제하여 교정하였으나 이것은 수직 벡터만을 고려한 것으 로 안쪽눈구석주름을 고려하지 않아 접선 벡터를 해소하지 못해 효과적인 교정이 어려웠다. 접선 벡터에 의한 중요성 은 Kim et $\mathrm{al}^{7}$ 연구에서도 볼 수 있는데 아래덧눈꺼풀로 인 하여 각막-속눈썹 접촉이 가장 많은 곳은 코쪽 부분(58.6\%) 이 차지하고 있으며 재수술하는 비율 역시 코쪽 영역에 속 눈썹이 접촉된 경우가 가장 많았다(3.2\%). 또한 $\mathrm{Oh}$ and $\mathrm{Lee}^{3}$ 연구에서는 수직 벡터 교정 없이도 접선 벡터 단독 교정만 으로도 덧눈꺼풀을 효과적으로 교정하였다고 보고하였다. 가장 최근에 보고된 연구에서는 변형호쯔방법 단독보다는 변형호쯔방법과 안쪽눈구석주름교정술을 동시에 시행할 경 우 덧눈꺼풀교정이 더 효과적이었다고 보고하였다. ${ }^{16}$

안쪽눈구석주름은 1828 년 Schön에 의해 처음 기술되었 고, ${ }^{6} 1841$ 년 Von Ammon에 의해 명명되었다. ${ }^{17,18}$ 임신 3개 월에서 6 개월 사이에 모든 인종에서 나타나며 서양인에서 는 사춘기가 되어 콧대가 완전히 발달되면 대개 소실되는 경향이 있으나 동양인에서는 안쪽눈구석주름이 어른이 되 어도 남아있는 경우가 많다.

안쪽눈구석주름의 원인은 불명확하나 코쪽 피부의 발달 저하, 두개골의 발달이 지연되어 여분의 피부가 남아서 주 름 생성, 과도한 눈둘레근, 주름밑의 섬유화된 지방조직, 눈 둘레근에 의한 비정상적인 피부장력 등이 원인으로 제시되 고 있다. ${ }^{5,17}$ 안쪽눈구석주름교정술의 방법은 Mustardé법, ${ }^{8}$
변형된 Y-V 앞옮김술(modified Y-V advancement, ${ }^{9,10}$ 뿌리 $\mathrm{Z}$-안쪽눈구석주름교정술(root Z-epicanthoplasty), ${ }^{5,10}$ 피부재 배치법(skin-redraping epicathoplasty), 등 다양한 방법이 소개되었는데 보통 술자가 익숙한 방법을 선택해 왔다.

Kwon et $\mathrm{al}^{10}$ 연구에서 변형된 Y-V 앞옮김술 후 반흔이 $67 \%$ (6명 중 4명)에서 발생하였으며 변형된 Y-V 앞옮김술 을 시행 받은 환아보다 뿌리 Z-안쪽눈구석주름성형술을 시 행 받은 환아에서 비후성반흔이 적게 관찰된다고 하였다. 하지만 뿌리 Z-안쪽눈구석주름 성형술은 도안이 복잡하여 술자마다 교정량의 차이를 보일 수 있으며 본 저자들의 수 술법보다 피부절개 및 피부판박리가 많아 흥터가 더 남을 수 있다. 피부 재배치법은 안쪽눈구석의 수평 방향의 피부 량을 줄이고 여분의 피부를 아래눈꺼풀을 따라 수평 방향 으로 재배치하여 안쪽눈구석주름을 교정하는 방법으로 뿌 리 Z-안쪽눈구석주름성형술에 비하여 도안이 쉽고 수직방 향으로 형성되는 절개선이 없어 수술 흥터가 잘 안보이는 장점이 ${ }^{11,19}$ 이 있으나 뿌리 Z-안쪽눈구석주름성형술과 마찬 가지로 비교정 피부절개가 길고 이에 따른 수술 흥터와 아 래눈꺼풀 안쪽 아래까지 절개를 하고 봉합을 하기 때문에 아래덧눈꺼풀교정술과 함께 수술하기에 적합하지 않으며 개귀모양 변형(dog-ear deformity)이 잘 발생할 수 있다.

본 연구에서 아래덧눈꺼풀교정술과 Hiraga 방식의 최소 절개로 안쪽눈구석교정술을 시행 받은 환자에서 비후성 반 흔이 관찰되지 않았는데 이러한 이유는 다른 수술법에 비 해 코쪽 피부를 덜 침범하고 피부절개가 단순하고 이에 따 른 피부봉합이 적기 때문이라고 생각된다. 아래덧눈꺼풀과 안쪽눈구석주름의 교정에 있어서 아래덧눈꺼풀의 수직 방 향과 접선 방향의 벡터를 고려해 수술을 해야 교정 효과가 좋고 재발이 적으며 최소 절개법은 술기가 쉬우며 흥터를 예방하는 데 도움이 된다.

본 연구는 후향적으로 의무 기록을 분석한 연구로 대상 환자 수가 적고, 치료 방법의 대조군이 없었지만 기존의 Jung et $\mathrm{al}^{20}$ 연구에서 아래덧눈꺼풀교정술과 피부재배치법 을 했을 경우 재발이 없었으며 본 저자가 최소 절개 안쪽눈 구석주름교정술을 사용하기 전 아래덧눈꺼풀교정술과 피 부재배치법을 시행한 56 명의 환자에서도 재발이 없었다. 마찬가지로 본 연구에서도 재발이 없었으므로 피부재비치 법보다 최소 절개 안쪽눈구석주름교정술의 술기가 더 간단 하고 경과 관찰기간 동안 재발이 없었다는 결과는 의의가 있다고 하겠다. 결론적으로 아래덧눈꺼풀이 있는 환자에서 안쪽눈구석주름이 심한 경우 덧눈꺼풀교정수술과 더불어 안쪽눈구석주름교정술을 시행하여 좋은 교정 효과와 미용 적 효과를 얻을 수 있었으며 도안이 쉽고 절개가 간단한 최 소 절개 안쪽눈구석주름교정술은 다른 수술법에 비해 효과 
적인 수술 방법이라 생각된다.

\section{REFERENCES}

1) Quickert MH, Wilkes TD, Dryden RM. Nonincisional correction of epiblepharon and congenital entropion. Arch Ophthalmol 1983;101:778-81.

2) Millman AL, Mannor GE, Putterman AM. Lid crease and capsulopalpebral fascia repair in congenital entropion and epiblepharon. Ophthalmic Surg 1994;25:162-5.

3) Oh JJ, Lee KW. Medial lower lid epiblepharon repair solely by skin-redraping medial epicanthoplasty. Br J Ophthalmol 2014;98: 1437-41.

4) Asamura $S$, Nakao $H$, Kakizaki $H$, Isogai N. Is it truly necessary to add epicanthoplasty for correction of the epiblepharon? J Craniofac Surg 2013;24:1137-40.

5) Yoo WM, Park SH, Kwag DR. Root Z-epicanthoplasty in Asian eyelids. Plast Reconstr Surg 2002;109:2067-71; discussion 2072-3.

6) Ahn JH, Byon DS, Lee HS. Epicanthus as a cause of pruritis. J Korean Ophthalmol Soc 2000;41:1292-6.

7) Kim JS, Jin SW, Hur MC, et al. The clinical characteristics and surgical outcomes of epiblepharon in Korean children: a 9-year experience. J Ophthalmol 2014;2014:156501.

8) Yoon K. Modification of Mustardé technique for correction of epicanthus in Asian patients. Plast Reconstr Surg 1993;92:1182-6.

9) Kao YS, Lin CH, Fang RH. Epicanthoplasty with modified Y-V advancement procedure. Plast Reconstr Surg 1998;102:1835-41.
10) Kwon MJ, Woo KI, Chang HR. Surgical correction for upper lid epiblepharon and epicanthal fold in children. J Korean Ophthalmol Soc 2005;46:1441-6.

11) Oh YW, Seul CH, Yoo WM. Medial epicanthoplasty using the skin redraping method. Plast Reconstr Surg 2007;119:703-10.

12) Woo KI, Yi K, Kim YD. Surgical correction for lower lid epiblepharon in Asians. Br J Ophthalmol 2000;84:1407-10.

13) Noda S, Hayasaka S, Setogawa T. Epiblepharon with inverted eyelashes in Japanese children. I. Incidence and symptoms. Br J Ophthalmol 1989;73:126-7.

14) Hwang JM, Lee JH. Clinical evaluation of epiblepharon. J Korean Ophthalmol Soc 1988;29:1-5.

15) Lim WK, Rajendran K, Choo CT. Microscopic anatomy of the lower eyelid in Asians. Ophthalmic Plast Reconstr Surg 2004;20:207-11.

16) Ni J, Shao C, Wang K, et al. Modified Hotz procedure combined with modified Z-epicanthoplasty versus modified Hotz procedure alone for epiblepharon repair. Ophthalmic Plast Reconstr Surg 2017;33:120-3.

17) Hong KR, Nam JW, Rhee MG. A clinical study on Rovda operation in epicanthus. J Korean Ophthalmol Soc 1982;23:147-51.

18) Park SW, Jeong SK, Park YG. Morphological evaluation of upper eyelid in Korean children. J Korean Ophthalmol Soc 1999;40:883-9.

19) Chung YJ, Kong JS, Kim YW, Kang SR. Restoration of the medial epicanthal fold: reverse skin redraping method in patients unsatisfied with epicanthoplasty. Ann Plast Surg 2013;71:456-60.

20) Jung JH, Kim HK, Choi HY. Epiblepharon correction combined with skin redraping epicanthoplasty in children. J Craniofacial Surg 2011;22:1024-6. 


\section{$=$ 국문초록 $=$}

\section{아래덧눈꺼풀교정술과 최소 절개 안쪽눈구석주름교정술의 임상결과}

목적: 심한 안쪽눈구석주름을 동반한 아래덧눈꺼풀 환자에서 아래덧눈꺼풀교정술과 최소 절개 안쪽눈구석주름교정술 방법을 소개하 고 이 방법의 임상결과를 보고하고자 한다.

대상과 방법: 2015년 1월부터 2019월 1월 사이 아래덧눈꺼풀교정술과 최소절개 안쪽눈구석주름교정술을 함께 받은 환자의 의무기록을 후향적으로 조사하였다. 39 명의 78 안을 최소 6 개월 이상 경과 관찰하면서 수술 결과, 주관적인 증상, 재발, 그리고 합병증에 대해 알아보았다.

결과: 총 39 명의 환자 중 남자는 14 명, 여자는 25 명이었다. 평균 나이는 $8.4 \pm 4.3$ 세였고 평균 추적 관찰기간은 $14 \pm 5.2$ 개월이었다. 39 명(100\%)의 환자가 최종 경과 관찰 시점까지 재발 없이 모양과 기능이 잘 유지가 되었다.

결론: 아래덧눈꺼풀 환자에서 안쪽눈구석주름이 심한 경우 수술 후의 안쪽 눈썹찔림 재발을 방지하기 위해 덧눈꺼풀교정수술과 함께 안쪽눈구석주름교정술을 같이 시행하는데 최소 절개 안쪽눈구석주름교정술(히라가 법)은 도안 및 술기가 쉽고 간단하며 교정 효과가 우수하였다.

〈대한안과학회지 2020;61(6):591-596〉

안지선 / Ji Seon An 새빛안과병원

Saevit Eye Hospital

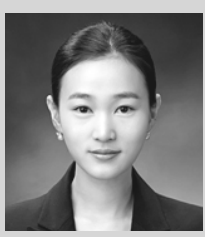

